\title{
Storm-time total electron content and its response to penetration electric fields over South America
}

\author{
P. M. de Siqueira ${ }^{1}$, E. R. de Paula ${ }^{1}$, M. T. A. H. Muella ${ }^{2}$, L. F. C. Rezende $^{1}$, M. A. Abdu ${ }^{1}$, and W. D. Gonzalez ${ }^{1}$ \\ ${ }^{1}$ National Institute for Space Research, INPE, Av. dos Astronautas 1758, Jardim da Granja, 12227-010, São José dos \\ Campos-SP, Brazil \\ ${ }^{2}$ Universidade do Vale do Paraíba, UNIVAP, Laboratório de Física e Astronomia, IP\&D, Av. Shishima Hifumi 2911, \\ Urbanova, 12244-000, São José dos Campos-SP, Brazil
}

Received: 30 May 2011 - Revised: 1 September 2011 - Accepted: 20 September 2011 - Published: 10 October 2011

\begin{abstract}
In this work the response of the ionosphere due to the severe magnetic storm of 7-10 November 2004 is investigated by analyzing GPS Total Electron Content (TEC) maps constructed for the South America sector. In order to verify the disturbed zonal electric fields in South America during the superstorm, ionospheric vertical drift data obtained from modeling results are used in the analysis. The vertical drifts were inferred from $\Delta H$ magnetometer data (Jicamarca-Piura) following the methodology presented by Anderson et al. (2004). Also used were vertical drifts measured by the Jicamarca ISR. Data from a digisonde located at São Luís, Brazil $\left(2.33^{\circ} \mathrm{S}, 44.2^{\circ} \mathrm{W}\right.$, dip latitude $\left.0.25^{\circ}\right)$ are presented to complement the Jicamarca equatorial data. Penetration electric fields were observed by the comparison between the equatorial vertical drifts and the Interplanetary Electric Field (IEF). The TEC maps obtained from GPS data reflect the ionospheric response over the South America low-latitude and equatorial region. They reveal unexpected plasma distributions and TEC levels during the main phase of the superstorm on 7 November, which is coincident with the local post-sunset hours. At this time an increase in the prereversal enhancement was expected to develop the Equatorial Ionization Anomaly (EIA) but we observed the absence of EIA. The results also reveal well known characteristics of the plasma distributions on 8,9 , and 10 November. The emphasized features are the expansion and intensification of EIA due to prompt penetration electric fields on 9 November and the inhibition of EIA during post-sunset hours on 7, 8, and 10 November. One important result is that the TEC maps provided a bi-dimensional view of the ionospheric changes offering a spatial description of the electrodynamics involved,
\end{abstract}

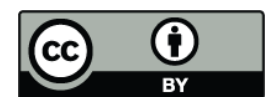

Correspondence to: P. M. de Siqueira (patricia.mara@dae.inpe.br) which is an advantage over TEC measured by isolated GPS receivers.

Keywords. Ionosphere (Electric fields and currents; Equatorial ionosphere; Ionospheric disturbances)

\section{Introduction}

The complex effects of magnetospheric convection in ionospheric electric fields and currents from middle to low latitudes during geomagnetic disturbances have been documented in several studies (Blanc, 1983; Heelis and Coley, 1992; Fejer, 1997; Foster and Rich, 1998; Kelley et al., 1979, 2003; Huang et al., 2005a, b; Mannucci et al., 2008). Under geomagnetically disturbed conditions, the two main sources of electric fields responsible for changes in the plasma drifts and for current perturbations are the prompt penetration electric fields (PPEFs) and the long lasting ionospheric disturbance dynamo (DD) electric fields. In this work both features are observed during a very intense geomagnetic storm that occurred on November 2004. In this paper we refer to "electric fields" as the convective features of the plasma flow velocity. As discussed by Vasyliūnas (2001, 2005a, b), the only parameter observed in the solar wind as well as in the magnetosphere and ionosphere is the plasma flow velocity $\boldsymbol{V}$ and not the electric field $\boldsymbol{E}$. However, by the use of the MHD approximation $\boldsymbol{E}=-\boldsymbol{V} \times \boldsymbol{B}$ it is possible to infer $\boldsymbol{E}$, which presents mathematical and conceptual advantages (Tsurutani et al., 2008a) in the description of the electrodynamics phenomena that will be discussed further.

The ionospheric disturbance dynamo is due to the dynamic action of thermospheric winds produced by auroral heating during the storm time. These winds modify the global circulation, generating disturbed ionospheric electric fields at

Published by Copernicus Publications on behalf of the European Geosciences Union. 
middle and low latitudes (Blanc and Richmond, 1980) and causing variations in thermospheric composition and densities (Rishbeth, 1975). The DD electric fields have timescales from a few to several hours (Fejer and Scherliess, 1997; Scherliess and Fejer, 1997). Relatively fast DD (occurring about $2-3 \mathrm{~h}$ after increases in convection) is attributed to the dynamo action of fast traveling equatorward wind surges (Fuller-Rowell et al., 2002), while slower changes in the electrodynamics (occurring 3-12 $\mathrm{h}$ later) are probably driven by the mechanism proposed by Blanc and Richmond (1980) of equatorward enhanced winds due to auroral heating (Fejer et al., 2007). The quiet time wind dynamo electric field at the ionosphere has a dawn-to-dusk polarity, while the DD electric field points from dusk-to-dawn (i.e. westward in the dayside and eastward at night). Thereby, during the action of DD mechanism the dawn-to-dusk component of the quiet zonal electric field tends to diminish or even reverse.

The penetration electric fields events were at first deduced from their consequent magnetic field observed in the equatorial electroject (Nishida, 1968). Several researchers observed that the interplanetary electric field (IEF) could penetrate into the magnetosphere-ionosphere system (Reddy et al., 1979). One explanation was found when Gonzales et al. (1979) showed that the ionospheric zonal electric field at the equator had the same structure as the auroral electric field. Kelley et al. (1979) proposed the concepts of "undershielding" and "overshielding" of the electric field by the Alfvén layer. According to those concepts, IEF penetrates to the low-latitude ionosphere and has significant influence on the ionospheric electrodynamics during intense geomagnetic storms. The penetration of IEF is influenced by the hot magnetospheric plasma that is the source of the Region2 field-aligned currents (FACs). Moreover, theory suggests that Region-1 FACs and their horizontal closure currents (de la Beaujardiere et al., 1993) play an important role in generating global ionospheric electric fields and that these currents respond straightly to the orientation and magnitude of the interplanetary magnetic field and to solar wind conditions such as the ion velocity and dynamic pressure (Mannucci et al., 2008). During steady conditions the deflection of charges in the ring current generates a dusk-to-dawn electric field in the inner magnetosphere configuring the shielding layer. The undershielding process is related to rapid and significant southward IMF variations associated with an increase in the magnetospheric convection and an enhanced dawn-to-dusk IEF. In this case the shielding layer becomes temporarily ineffective and the IEF penetrates into the inner magnetosphere and enhances the quiet ionospheric zonal electric field (dawn-todusk). The overshielding is assumed to occur if the magnetospheric convection is suddenly weakened when the IMF turns from southward to northward. In this case the shielding charges will be the source of a dusk-to-dawn electric field in the inner magnetosphere and the result will be an eastward electric field in the nightside ionosphere and a westward electric field on the dayside (Kelley et al., 1979). On the other hand, the concepts of "undershielding" and "overshielding" are not being considered in some recent studies (Huang et al., 2005a, b; Mannucci et al., 2005; Tsurutani et al., 2004, 2008a). Such studies propose a long duration prompt penetration of IEF to ionosphere during large southward incursions of IMF $B_{\mathrm{Z}}$ and a great uplift of ionospheric plasma with a resulting enhanced TEC. The latter is believed to enhance due to the formation of a "superfountain" effect which has been called the "dayside ionospheric superfountain (DIS) effect". Also, Tsurutani et al. (2008a) propose the idea of penetration of the dusk-to-dawn IEF, i.e. during northward IMF $B_{\mathrm{Z}}$ turnings, and discuss one event sustaining this hypothesis. Generally, the PPEFs have typical rise and decay of about 15 min duration, and lifetimes of about one hour (Gonzales et al., 1979; Fejer, 1986) to several hours (Huang et al., 2005a, b; Mannucci et al., 2005; Tsurutani et al., 2004, 2008a).

The changes in the equatorial ionization anomaly (EIA) are one of the most perceptible responses of the equatorial thermosphere-ionosphere system to the magnetospheric disturbances (Abdu et al., 1993). These changes can be caused by the discussed modifications in the ionospheric electric fields and also by thermospheric winds (Prölss, 1995). The EIA is attributed to the so-called fountain effect. We intend to show such changes by analyzing TEC maps. The disturbed electric fields at the ionosphere during active times lead to large changes in dayside TEC at low and middle latitudes, and the physical mechanisms involved in these changes are well understood (Fuller-Rowell et al., 1997; Tsurutani et al., 2004, 2007, 2008a, b; Huba et al., 2005; Lin et al., 2005). This study presents TEC maps for the South America region in addition to ionospheric vertical drifts at the equator and magnetospheric parameters to evaluate the global ionospheric scenario in this region during the November 2004 superstorm. The low-latitude ionosphere is quite sensitive to geomagnetic storms and this study intends to address some features of this electrodynamic region.

\section{Methodology}

The geomagnetic data used in this work were obtained from Kyoto WDC database. We used the planetary Kp index as indicator of global geomagnetic disturbances and the Sym-H index to verify the phases of the geomagnetic storm. The effects of the solar wind dynamic pressure variations are more clearly seen in the Sym-H than in Dst index (Iyemori, 1990).

In this study we present vertical drifts at geomagnetic equator. The ionospheric zonal electric fields can be estimated from the vertical drifts using the relationship: $V_{\text {drift }}=$ $E / B$ (where $E$ is the zonal electric field and $B$ is the magnitude of geomagnetic field at the geomagnetic equator). It is not our intention to verify any proportionality factor between the IEF and the zonal electric field. Fejer et al. (2007) showed that this type of evaluation during the penetration electric 
fields events in the superstorm of 7-10 November 2004 is not applicable and demands the analysis and insertion of other dynamic issues that are not expressed by simple proportionality factors. In contrast, Kelley et al. (2010) suggest that a simple empirical scaling relationship between interplanetary electric field (IEF) and low-latitude penetration electric is often valid-although this type of evaluation will not be explored here. Thus, we will present the vertical drifts (not the electric fields) at the geomagnetic equator and use this parameter to discuss qualitatively the disturbances in the zonal electric fields.

Anderson et al. (2004) presented and validated a suitable methodology to calculate the diurnal vertical drifts using the dual magnetometer technique. They applied a least mean square method (LSM) in order to obtain a polynomial which consists in the $\Delta H$ as main variable. $\Delta H$ is the difference in the magnitudes of the horizontal component of geomagnetic field between a magnetometer placed directly on the magnetic equator and one displaced $6^{\circ}-9^{\circ}$ away. The basis of this method was first proposed by Rastogi and Klobuchar (1990). The $\Delta H$ provides a realistic approximation for the daytime ionospheric vertical drifts since it is related to the equatorial electrojet strength. The polynomial approach from Anderson et al. (2004) was successfully applied by Huang et al. (2005a, b). Anderson et al. (2004) also developed and trained a neural network (NN) using the historical vertical drifts data from Jicamarca radar and showed that the NN presented a better performance compared to the LSM. Based on this we decided to perform a NN taking into account the same criteria of Anderson et al. (2004). Our neural network outputs will provide a very adequate storm-time analyzing tool. It is worth mentioning here that the results are for the Peruvian sector (Jicamarca). The daytime (07:00 LT-17:00 LT) equatorial vertical drifts at Jicamarca from 7-8 November were simulated using the NN, which data inputs were: year, month, day, local time, daily Ap, Kp, F10.7 and $\Delta H$ (Jicamarca-Piura magnetometer data). Our NN was trained using the Jicamarca vertical drift database available from 2001 to 2006. The simulation results have an r.m.s. error of $\sim 3 \mathrm{~m} \mathrm{~s}^{-1}$. For the 7-8 November period we used digisonde data from Jicamarca to calculate the vertical drifts during the pre-reversal enhancement. From 9-10 November the vertical drifts measured by the Jicamarca Incoherent Scatter Radar were used. We present the average drifts since the drifts do not change significantly with height (Woodman, 1970; Fejer et al., 2007). By the use of the F layer bottomside height $\left(h^{\prime} F\right)$ measured by a digisonde located at Jicamarca, we also calculated its time rate of change $\left(d h^{\prime} F / d t\right)$, during the dusk hours, when this bottomside is above $300 \mathrm{~km}$ (Bittencourt and Abdu, 1981), which is most often the case near dusk thus we only performed this calculation for dusk hours. We performed this calculation in order to complement the diurnal vertical drifts obtained by the NN.

We present additional data with Brazilian digisonde observations of $h^{\prime} F$. For the Brazilian digisonde data, we present the isolines measured in the range from 3 to $9 \mathrm{MHz}$ showing the height of ionosphere. The brazilian digisonde is located at the equatorial station of São Luís $\left(2.33^{\circ} \mathrm{S}, 44.2^{\circ} \mathrm{W}\right.$, dip latitude $0.25^{\circ}$ ).

The solar wind plasma and magnetic field parameters measured by the ACE satellite were obtained from the High Resolution Omni (OmniWeb - NASA). This solar wind database has a time delay correction corresponding to the travelling time between the instant of ACE observation and the instant of interaction at the magnetopause.

In order to verify the polar cap activity the PC-index was used, which is the Polar Cap Index determined from the North station at Thule, Greenland. It was computed at World Data Center for Geomagnetism, Copenhagen at the Danish Meteorological Institute: http://web.dmi.dk/projects/wdcc1/.

The dawn-to-dusk component of the IEF was calculated as $E_{\mathrm{y}}=V_{\mathrm{SWx}} B_{\mathrm{z}}-V_{\mathrm{SWz}} B_{\mathrm{x}}$ in solar magnetospheric coordinates (GSM). Positive (negative) $E_{\mathrm{y}}$ is directed approximately duskward (dawnward) in the magnetospheric equatorial plane.

We also calculated the geoeffective IEF $E_{\mathrm{y}}$ for penetration of electric field that is defined by $E_{\mathrm{rec}}=V_{\mathrm{SW}} B_{T} \sin ^{2}(\theta / 2)$ where $V_{\mathrm{SW}}$ is the solar wind speed, $\theta$ is the "clock angle" between the z-axis and the $B_{T}$ transverse component of the IMF vector, where $\boldsymbol{B}_{T}=\boldsymbol{B}_{\mathrm{y}}+\boldsymbol{B}_{\mathrm{z}}$ GSM (Gonzalez et al., 1994). In other words, $\theta$ is the IMF clock angle in the Y-Z plane.

The $\theta$ angle has an important role since the energy rate injection is maximum if the geomagnetic field and IMF are anti-parallel $\left(\theta \approx 180^{\circ}\right)$, i.e. during magnetic reconnection at magnetopause, and is minimum if those fields are parallel $\left(\theta \approx 0^{\circ}\right)$ (Gonzalez and Tsurutani, 1987; Pulkkinen et al., 2002). The result of $E_{\text {rec }}$ is a half-wave rectification of the IEF, i.e. it takes into account only the positive (duskward) part of IEF $E_{\mathrm{y}}$ (Burton et al., 1975). The conceptual idea of $E_{\text {rec }}$ only considers the energy injection through reconnection which is enabled by southward turnings of IMF $B_{\mathrm{Z}}$.

The TEC measurements were obtained from dualfrequency Global Positioning System (GPS) data recorded from several arrays installed across the South America continent. The TEC maps were generated by the UNB-IMT program (University of New Brunswick Ionospheric Modeling Technique) (Komjathy, 1997). The UNB-IMT has a good precision when a dense receiver distribution is used. For ocean areas the TEC values calculated by UNB-IMT are not reliable since they are an interpolation result from very sparse receiver's distribution and the program does not apply any TEC model for these critical areas. The observation and navigation files for most of the sites used can be downloaded from Scripps Orbit and Permanent Array Center (SOPAC) Garner GPS archive (http://garner.ucsd.edu) and from the Data Center for Geosciences of the Brazilian Institute of Geography and Statistics (IBGE) at http://www.ibge.gov.br. 
2004

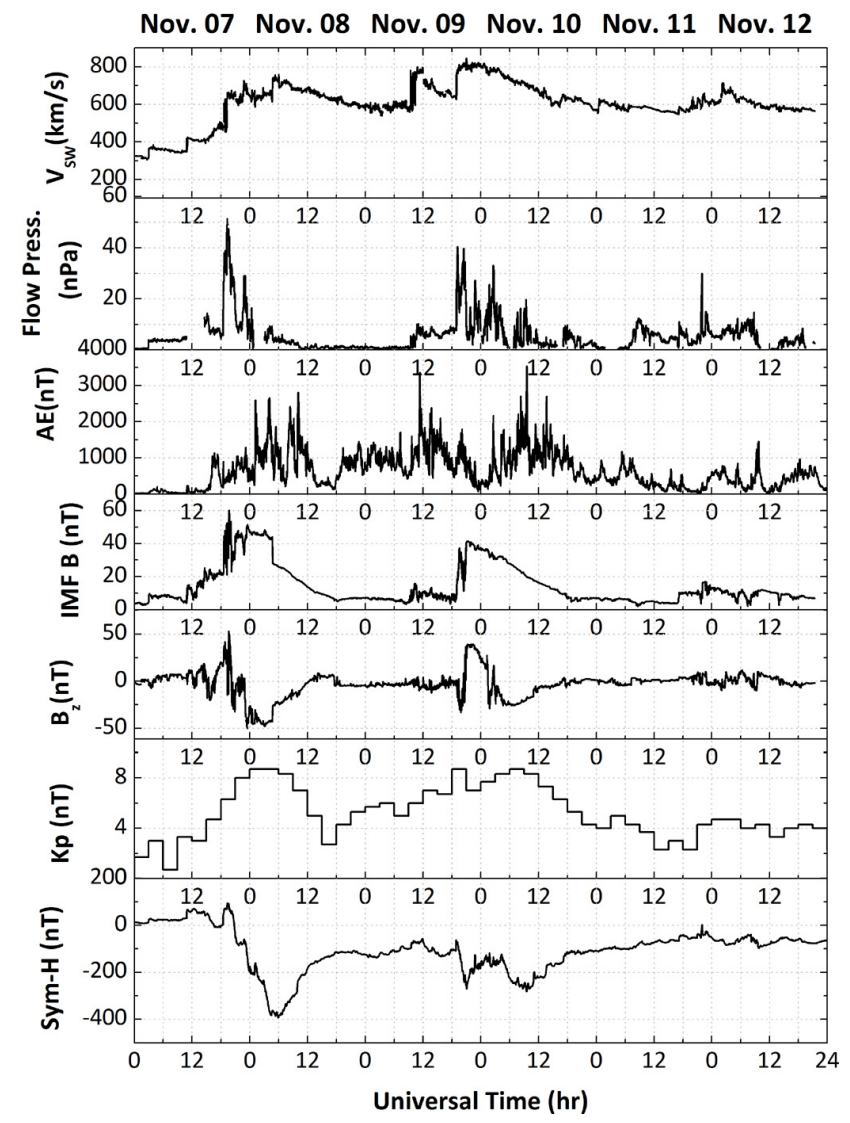

Fig. 1. From top to bottom: Solar wind speed; solar wind Flow Pressure; AE index; IMF magnitude $B$; IMF $B_{\mathrm{Z}}$ component; Kp index; and Sym-H index for the period 7-12 November 2004.

\section{Results and discussion}

In the present paper the main focus is the ionospheric response to the geomagnetic disturbances that occurred during the 7-12 November 2004 superstorm. A comprehensive discussion of the disturbed electric fields for this event can be found in the works of Fejer et al. (2007), Kelley et al. (2010), and Mannucci et al. (2008). A detailed description of the solar and interplanetary causes of the storm can be found in Tsurutani et al. (2008b) and Echer et al. (2010).

Figure 1 presents the geomagnetic indexes and solar wind conditions throughout 7-12 November 2004. The main responses for this complex event are described further.

\subsection{November 2004}

On 7 November, around $\sim 11: 30$ UT, the solar wind increases from $\sim 300 \mathrm{~km} \mathrm{~s}^{-1}$ to $\sim 400 \mathrm{~km} \mathrm{~s}^{-1}$ as seen in Fig. 1. This enhancement was probably associated with an increase in the flow pressure (Fig. 1, second panel), which was not seen in the gap of data for the period. At this time Sym-H presents a small enhancement probably due to a compres-

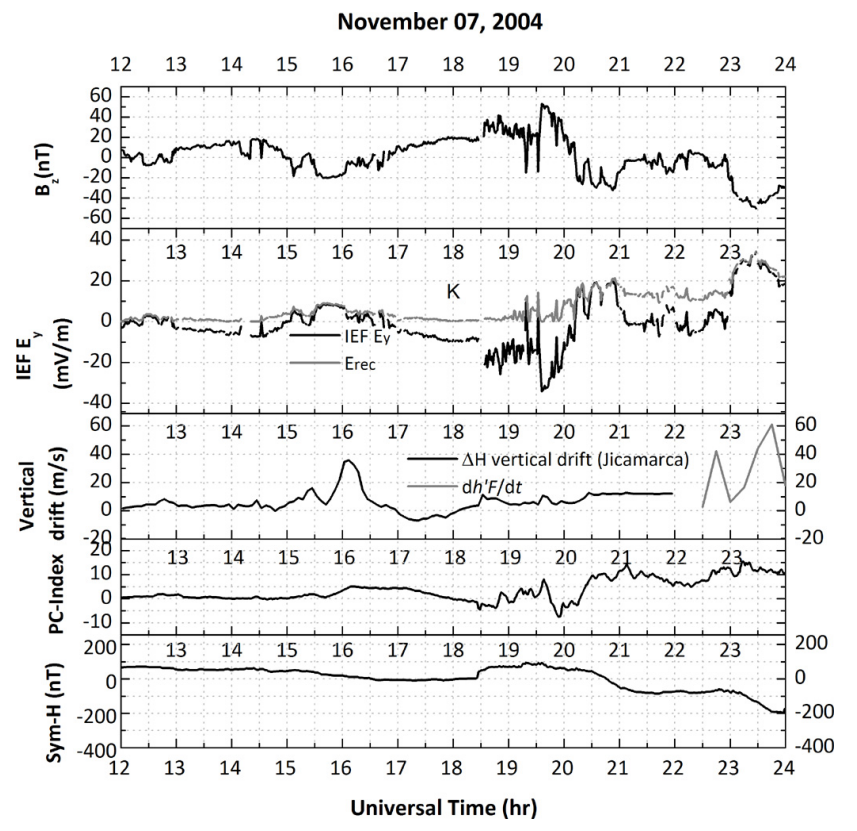

Fig. 2. From top to bottom: Interplanetary Magnetic Field $B_{\mathrm{Z}}$; Interplanetary Electric Field (IEF) $E_{\mathrm{y}}$ and $E_{\mathrm{rec}}$; Vertical drifts over Jicamarca (black line denotes vertical drifts simulated with the neural network using magnetometer $\Delta H$ Jicamarca-Piura data, gray line denotes the pre-reversal enhancement calculated from digisonde data at Jicamarca); PC-index to evaluate the polar cap activity; and Sym-H geomagnetic index showing the initial phase of the geomagnetic storm.

sion of the magnetopause. This subtle enhancement in solar wind speed and flow pressure was not responsible for the start of the storm initial phase but probably caused disturbances in ionospheric vertical drifts as we can see in Fig. 2 (quiet time patterns can be seen in Fejer et al., 2007). During the day the vertical drifts presented disturbed values (around zero), smaller compared to quiet times $\left(\sim 20 \mathrm{~m} \mathrm{~s}^{-1}\right)$. From about 15:30 UT (10:30 LT) until 16:30 UT (11:30 LT), the Jicamarca vertical drifts present a peak reaching $\sim 35 \mathrm{~m} \mathrm{~s}^{-1}$ (daytime maximum value). By comparing the vertical drifts with the IEF in this period, one can identify a correspondence between both curves, which we assumed as an event of prompt penetration electric field (PPEF) (the positive values of IEF between $\sim 15: 30$ UT and $\sim 16: 00$ UT are possibly the cause for the raise in the vertical drifts following this period). For this penetration event the TEC had no significant response relative to quiet time, except for slightly higher TEC absolute values on 7 November, as shown in Fig. 3. The markers presented in the TEC maps refer to the geographic position of GPS receivers used in the calculations. The regions with a good coverage of GPS receivers have a higher level accuracy in the TEC results. The data for 6 November are assumed as quiet time reference.

From 17:00 UT (12:00 LT - Jicamarca) until 18:00 UT (13:00 LT), the vertical drifts became negative. There are 

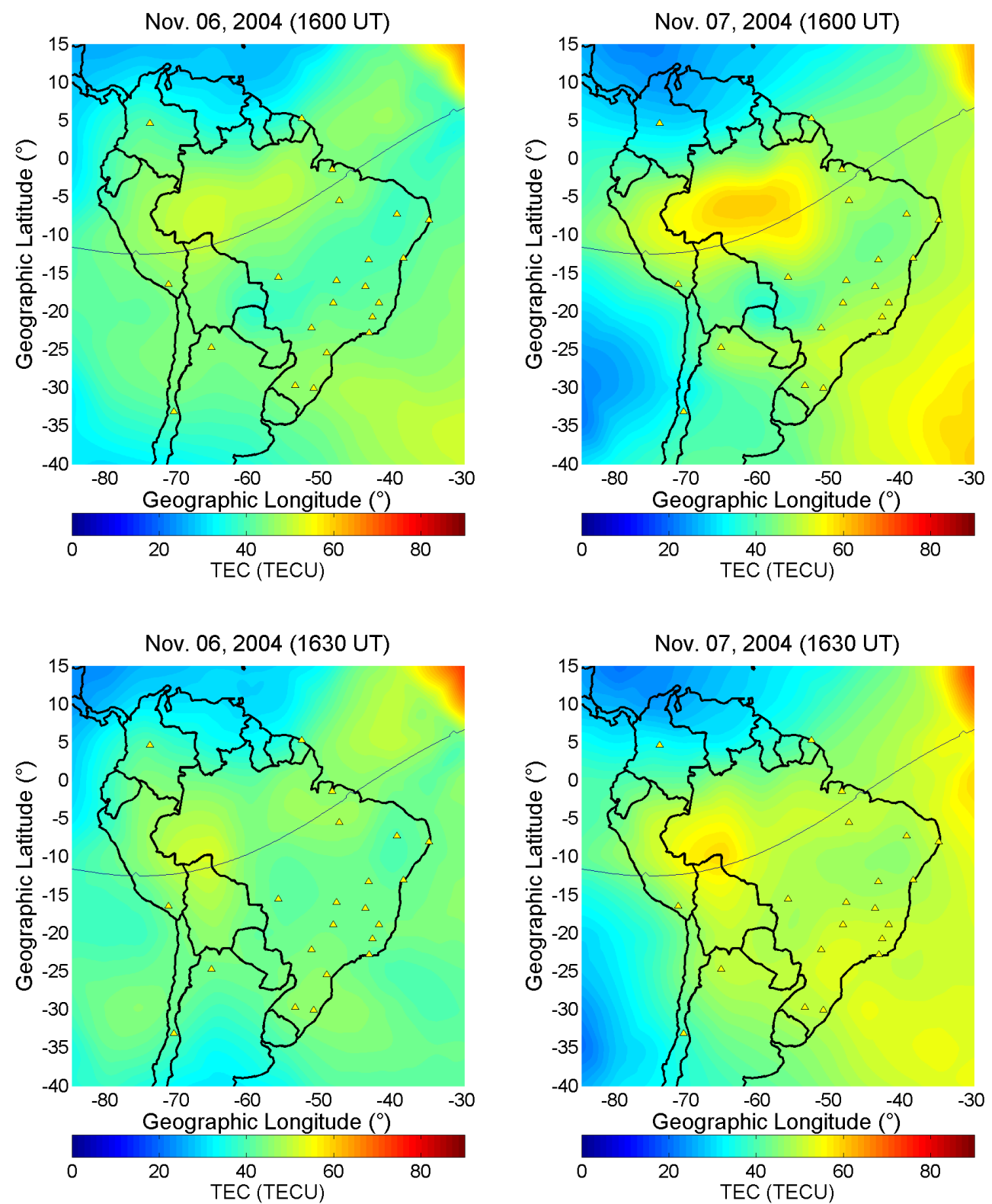

Fig. 3. Left: TEC map for 6 November (quiet day) at 16:00 UT (13:00 BST) (upper panel) and 16:30 UT (13:30 BST) (bottom panel). Right: respective TEC response on 7 November. The markers refer to the geographic position of GPS receivers used in the calculations.

two approaches to evaluate this result. The first one was discussed by Fejer et al. (2007) who argue that these particular vertical drifts are a result from a fast disturbance dynamo due to the injection of energy in the polar caps during the PPEF at $\sim 16: 00$ UT. The second one was proposed by Tsurutani et al. (2008a) and considers the hypothesis of the penetration of the dusk-to-dawn IEF, i.e. the westward IEF during $B_{\mathrm{Z}}$ northward turnings. They tested one event and found a correlation between a downward vertical drift over Jicamarca (during the day) and a dusk-to-dawn orientation of IEF. It is worth mentioning here that according to recent studies both approaches are accepted; therefore, more analysis is necessary of events similar to this to balance such points of view. In addition, the overall scenario of geomagnetic storms have to be considered to perform such analysis, and then the particular features of ionospheric electric fields during IMF $B_{\mathrm{Z}}$ northward turnings could be explained taking into account the current theories and data available up to now.

At about 18:30 UT (13:30 LT - Jicamarca), the solar wind speed reached $\sim 650 \mathrm{~km} \mathrm{~s}^{-1}$ associated to an increase in the flow pressure from $\sim 10 \mathrm{nPa}$ to $\sim 50 \mathrm{nPa}$. This shock compressed the magnetopause and caused the storm's sudden commencement associated to the increased Sym-H. For the following hours the PC-index shows an enhanced polar cap 

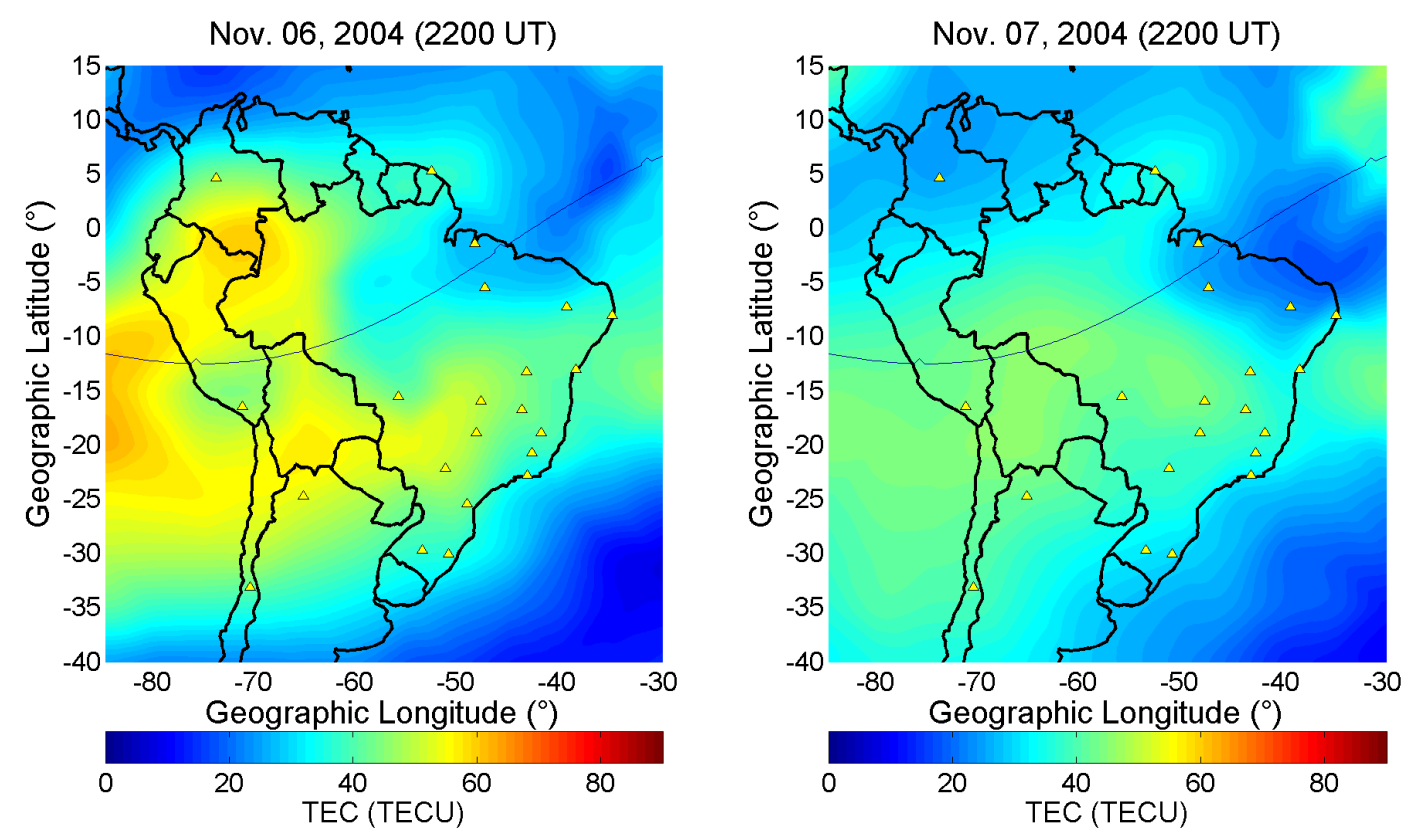

Fig. 4. Left: TEC map for the 6 November (quiet day) at 22:00 UT (19:00 BST). Right: respective TEC response on 7 November.

activity. $\quad B_{\mathrm{Z}}$ turns to south from 20:14 UT on 7 November and remains southward until 8 November at $\sim 12: 00$ UT (except for some minutes around 22:00 UT on 7 November). At $\sim 20: 45$ UT on 7 November (15:45 LT - Jicamarca; $17: 45$ BST), the main phase of the magnetic storm has initiated (denoted by Sym-H in Fig. 2). BST stands for "Brazil Standard Time" and is equivalent to the local time, i.e. UTC $-3 \mathrm{~h}$. The beginning of the storm's main phase was coincident with the pre-reversal enhancement (PRE) hours during the evening in the Brazilian region. During the southward IMF $B_{\mathrm{Z}}$ condition, the penetration of eastward IEF to ionospheric altitudes is favored and this scenario may lead to enhanced ionospheric fountain effect. Observations of such enhancement are found in Basu et al. (2001). The result is an enhanced EIA with prominent crests displaced to higher latitudes compared to quiet time patterns (Mendillo, 2006). The equatorial effects of combined PPEF and PRE are merely significant if PPEF is extremely large. For most cases PRE is predominant (Huba et al., 2005).

Figure 4 presents TEC maps for South America on 7 November at 22:00 UT (17:00 LT - Jicamarca; 19:00 BST). The enhanced fountain effect is not observed, and from the TEC maps in Fig. 4 one can realize that indeed there is a noticeable reduction in the TEC absolute values compared to the quiet day. As stated before, the vertical drifts presented a disturbed behavior (smaller values along day hours) during the whole day even prior to the first enhance in Sym-H. Thus, we attribute these smaller absolute TEC values to the disturbances in the daytime vertical drifts.

Figure 5 presents the $h^{\prime} F$ for the period 6-10 November from a digital ionosonde located at São Luís (Brazil) for

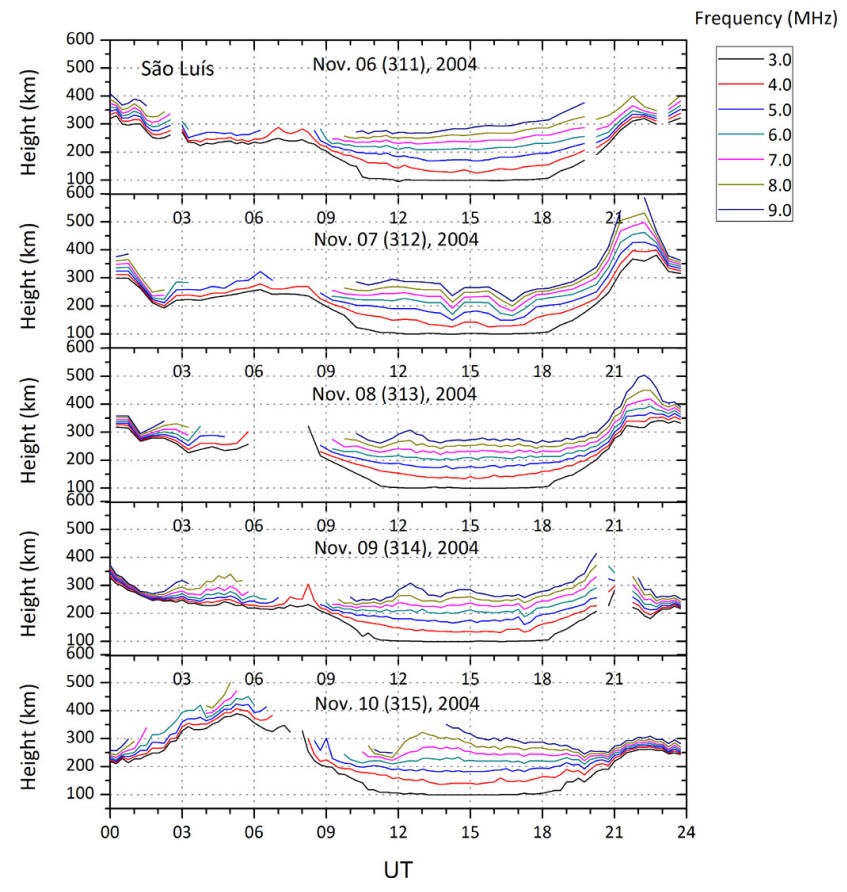

Fig. 5. Virtual height of the $\mathrm{F}$ layer measured by a digisonde located at São Luís, Brazil $\left(2.33^{\circ} \mathrm{S}, 44.2^{\circ} \mathrm{W}\right.$, dip latitude $\left.0.25^{\circ}\right)$.

the frequency range of 3-9 MHz. On 7 November it is evident the lowering of the $\mathrm{F}$ layer beginning at $\sim 15: 00 \mathrm{UT}$ (12:00 BST) compared to the quiet day. The lower values are related to the smaller vertical drifts shown in Fig. 2 as discussed earlier. The presence of lower positive vertical drifts 

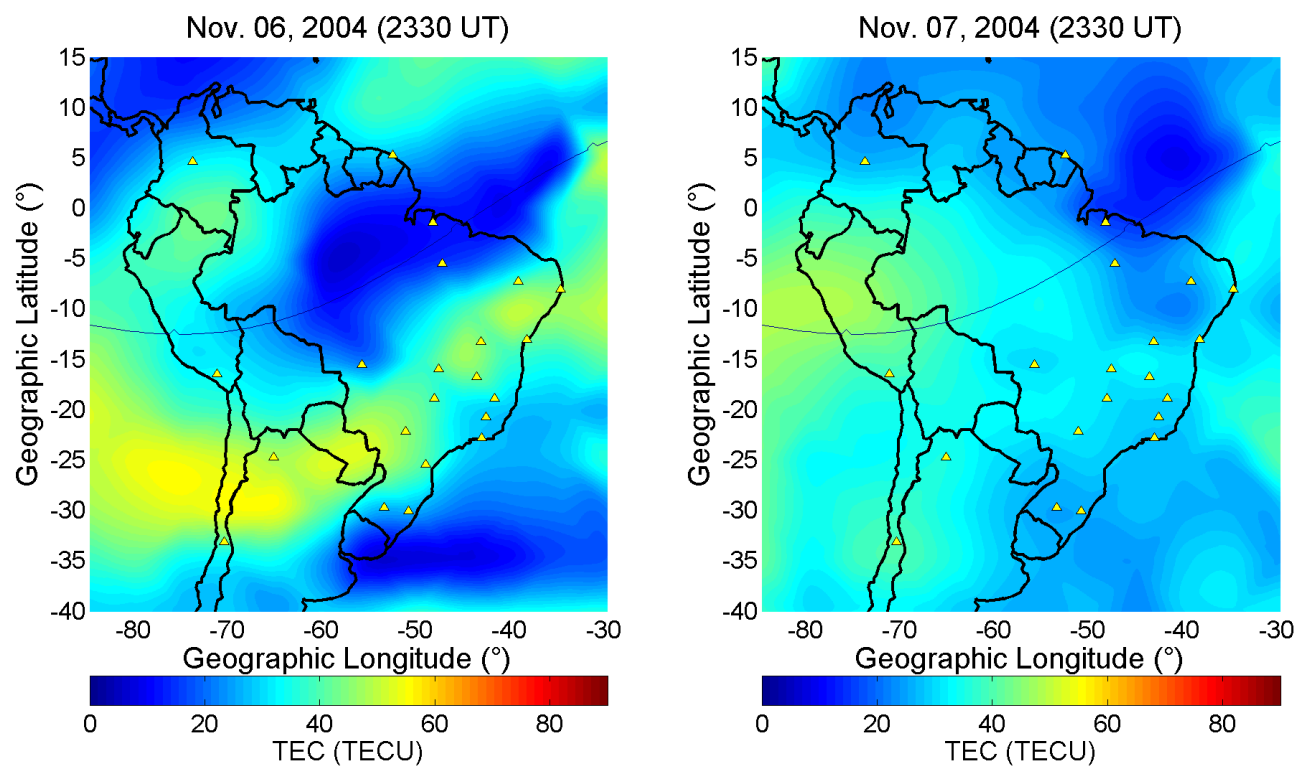

Fig. 6. Left: TEC map for the 6 November (quiet day) at 23:30 UT (20:30 BST). Right: the TEC response on 7 November for the same hour showing the EIA suppression.

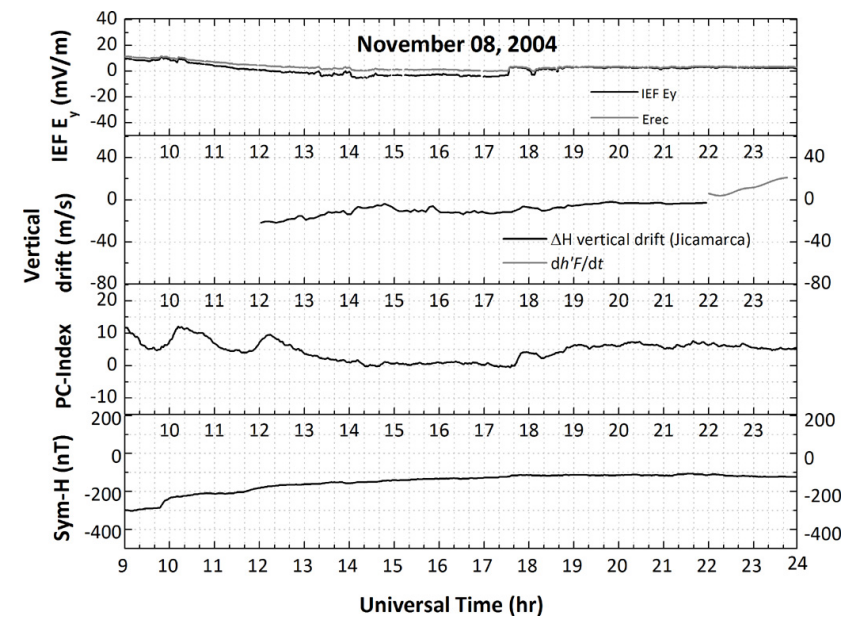

Fig. 7. IEF $E_{\mathrm{y}}$ and $E_{\mathrm{rec}}$, vertical drifts inferred from magnetometer (black line) and digisonde (gray line) at Jicamarca, PC-index denoting the auroral activity and the Sym-H indicating the recovery phase of the superstorm occurred on 7 November.

compared to a quiet day $\left(\sim 20 \mathrm{~m} \mathrm{~s}^{-1}\right)$ and negative vertical drifts after 17:00 UT (14:00 BST) were probably the reasons for such lowering of the $\mathrm{F}$ layer.

Figure 6 presents the TEC map for 7 November at 23:30 UT (18:30 LT - Jicamarca; 20:30 BST) (6 November as quiet day reference). The IEF of reconnection $\left(E_{\text {rec }}\right)$ at this moment is the maximum for this day. Although the pre-reversal enhancement is identified in the Jicamarca vertical drifts (and from Brazilian $h^{\prime} F$ data seen in Fig. 5), the development of EIA is absent. The negative vertical drifts that occurred around 17:00 UT (12:00 LT - Jicamarca; 14:00 BST) are a possible explanation for the inhibition of EIA on 7 November. We attribute the smaller absolute TEC values at 23:30 UT mostly to the disturbed vertical drifts. The observed results were TEC maps with absence of the EIA until the end of the day. Therefore, our hypothesis is that the combined effects of the negative vertical drifts $\sim 17: 00$ UT discussed earlier and the lower drifts along the day were possibly responsible for the EIA inhibition in the evening and post-sunset hours in South America during 7 November.

As stated before, the main phase of the geomagnetic storm is coincident with the sunset hours for the longitudinal sector studied here but 7 November 2004 is marked by unusual ionospheric responses for these hours.

\subsection{November 2004}

The beginning of 8 November is marked by the intense main phase of the geomagnetic storm. The magnetospheric and ionospheric conditions for this day are presented in Fig. 7 and the effects of such conditions are showen in Fig. 8. It is noticeable in Fig. 8 (panels a and e) the development of the southern crest of the EIA (asymmetric EIA), reaching low to middle latitudes (the region comprised between $25^{\circ} \mathrm{S}-35^{\circ} \mathrm{S}$ in Fig. 8e was attributed as a numerical error and has no physical meaning). The most realistic explanation for this is the action of a fountain effect leading to the EIA formation. Such fountain effect is assumed as a result of the vertical drifts seen in Fig. 2 at the very end of 7 November $(\sim 19: 00$ LT Jicamarca). The positive vertical drifts reaching $\sim 60 \mathrm{~m} \mathrm{~s}^{-1}$ are able to initiate the fountain effect for that longitude sector. Considering the IEF in the first plate of Fig. 2, it is possible 


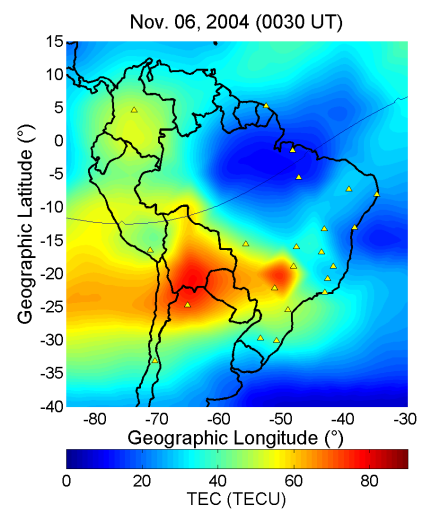

(a)

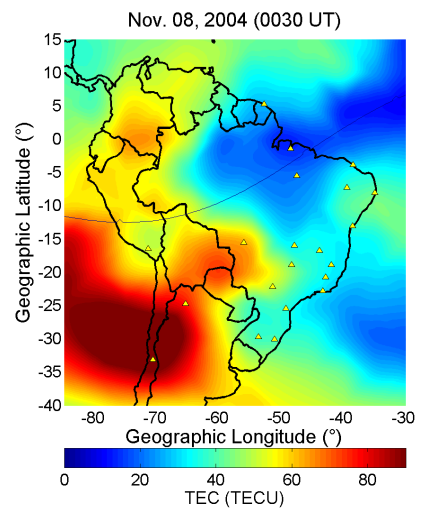

(e)

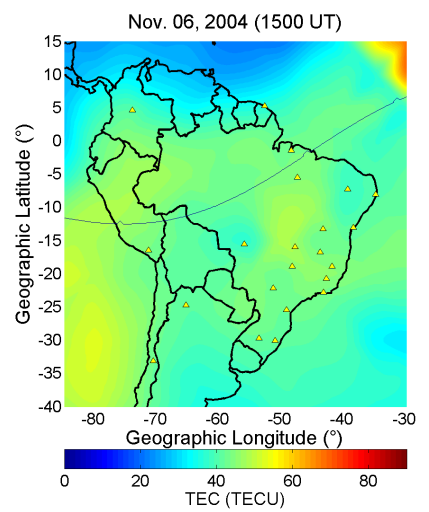

(b)

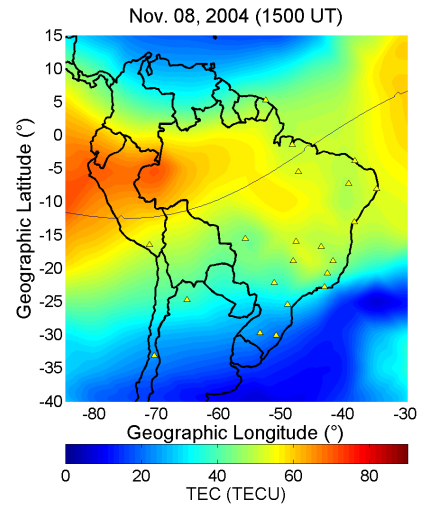

(f)

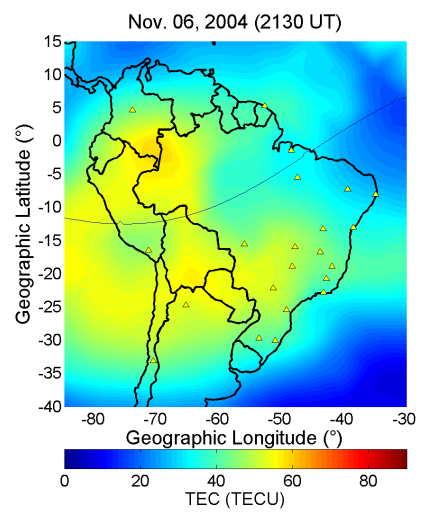

(c)

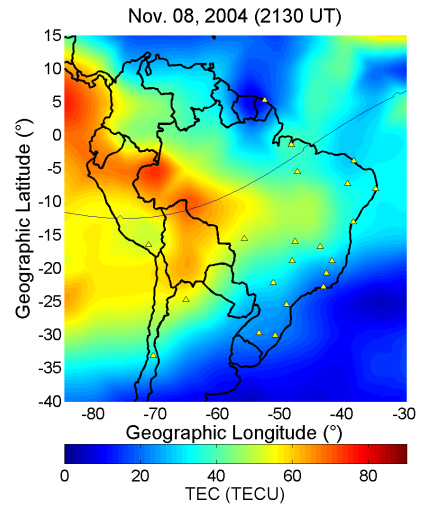

(g)

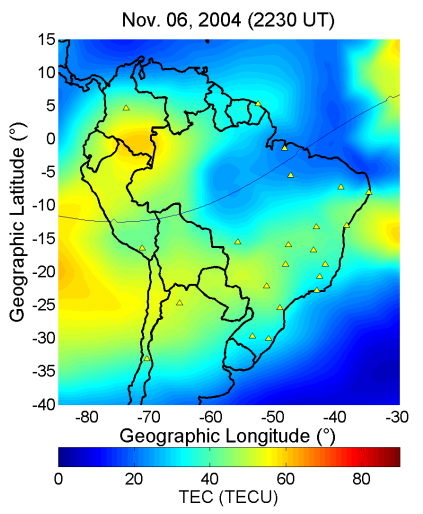

(d)

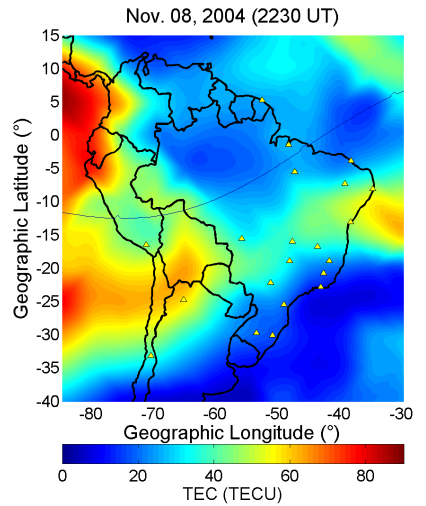

(h)

Fig. 8. TEC evolution for 8 November 2004. Top: TEC maps for 6 November (quiet day) at 00:30 UT (21:30 BST), 15:00 UT (12:00 BST), 21:30 UT (18:30 BST) and 22:30 UT (19:30 BST) (from a to d, respectively). Bottom: TEC maps at the respective hours for 8 November (from e to $\mathbf{h}$ ).

to attribute the increased vertical drift to a PPEF since there is a clear correspondence between IEF and the vertical drifts curves around 24:00 UT (19:00 LT - Jicamarca) on 7 November. It is clearly noticeable that the absolute TEC values are much higher whether compared to the quiet time. Asymmetric development of EIA (asymmetric crests) is often reported as a consequence of meridional winds (ionization is transported to the downwind side of the equator coming from the upwind side). The degree of such asymmetry would depend upon the competing forces of the wind velocity and the driving zonal electric field (Abdu, 1997; Muella et al., 2010).

During the main phase of a geomagnetic storm, the EIA crests are displaced to higher latitudes and one expects a decrease in daytime TEC over the geomagnetic equator and increase from low to middle latitudes. Moreover, the PPEF events are characterized by upward stormtime drifts on the dayside and downward drifts on the nightside (Fejer and Scherliess, 1997; Fejer, 2002; Tsurutani et al., 2008a), thus the maximal uplift of the ionosphere is expected around noon (LT). The main phase of this geomagnetic storm starts at 7 November 20:45 UT (15:45 LT - Jicamarca; 17:45 BST), lasting until 8 November $\sim 05: 50$ UT (00:50 LT - Jicamarca,
02:50 BST) when the recovery phase initiates. The minimum Sym-H value for this geomagnetic storm is $-394 \mathrm{nT}$, which occurred on 8 November, 05:55 UT, which is during nighttime hours for both Jicamarca and Brazil. The fact that the main phase of this geomagnetic storm is mostly during the nighttime hours for the longitudinal sector studied reflects in low TEC values observed for these hours. Even for the intense incursion of Sym-H during the main phase, the TEC maps for the nighttime hours did not present significant changes. Then, the development of EIA was not observed for these hours.

During daytime on 8 November the vertical drifts at Jicamarca present negative values as it is shown in Fig. 7. The Brazilian $h^{\prime} F$ digisonde data for this day (Fig. 5, third panel) also show a nearly steady $\mathrm{F}$ layer during daytime with no significant uplift. The plausible explanation for this result is the action of an ionospheric disturbance dynamo that reflected in smaller TEC absolute values at mid-latitudes, as seen in the TEC maps (Fig. 8f and 8g). Associated to the disturbed electric fields, at this point of the geomagnetic storm the changes in the neutral composition are often quite significant and may be an additional mechanism to reduce the 
absolute TEC values during 8 November, reflected in the negative phase of the ionospheric storm (Buonsanto, 1999). Mannucci et al. (2009) and Sahai et al. (2009) performed this type of evaluation. The inhibition of EIA prevailed during daytime until 22:00 UT (17:00 LT - Jicamarca, 19:00 BST) when a slight raise of the ionospheric plasma was able to develop the EIA over the South America region, as we can see from the vertical drifts in Fig. 7 and the TEC map in Fig. 8h (TEC values at the west side are purely numerical due to the lack of GPS receivers at that region).

\section{$3.3 \quad 9-10$ November 2004}

The vertical drifts measured by the Jicamarca ISR on 910 November show the most disturbed electric fields occurred in the November 2004 superstorm. Figure 9 shows the solar wind conditions for this period, the equatorial vertical drifts, and Sym-H index. A recurrent superstorm occurs on 9 November around 19:00 UT. The main phase prevails until 04:30 UT on 10 November with a second Sym-H descending lasting until $\sim$ 10:00 UT when the recurrent superstorm recovery phase starts. Therefore, daytime on 10 November is characterized by the recovery phase of the storm.

On 9 November the vertical drifts present a disturbed behavior during daytime in Jicamarca from 12:00 UT (07:00 LT) until 18:00 UT (13:00 LT) showing fluctuations without any significant increase in magnitude. The disturbed vertical drifts are probably due to the action of disturbance dynamo mechanism lasting until 19:00 UT (14:00 LT). From this time on the vertical drifts are suddenly raised and the correlation between the slopes of the IEF and the vertical drifts plots is clear. We attribute this result to a PPEF that caused the highest vertical drift ever measured by the Jicamarca ISR $\left(\sim 120 \mathrm{~m} \mathrm{~s}^{-1}\right)$. The PPEF at $\sim 19: 00$ UT is ensured by the $B_{\mathrm{Z}}$ southward turning (Fig. 1) and large magnitudes of the function $E_{\text {rec }}$.

The TEC maps seen from Fig. 10e to $\mathrm{h}$ show a large enhancement of TEC absolute values compared to the quiet day. The vertical drifts prior to 19:00 UT were mostly of disturbance dynamo type (Fig. 9) and could not produce such observed TEC enhancements. In this case the non electrodynamic forcing (composition changes and disturbed thermospheric winds) is more important in the competing scenario between the electric fields, disturbed winds, and the composition changes, being the most plausible explanation for this result.

The TEC enhancement is even more pronounced following the occurrence at $\sim 20: 00$ UT (15:00 LT - Jicamarca; 17:00 BST $)$ of the largest vertical drift $\left(\sim 120 \mathrm{~m} \mathrm{~s}^{-1}\right)$ measured for 9 November, as we can see from Fig. 10f. After 21:00 UT (16:00 LT - Jicamarca; 18:00 LT - Brazil), a strong development of the anomalous EIA initiates (Fig. 10g and h) with large TEC values and also expanding to a much wider latitude range. This feature prevails until the end of the day (TEC maps not shown), which we attribute to the "super-

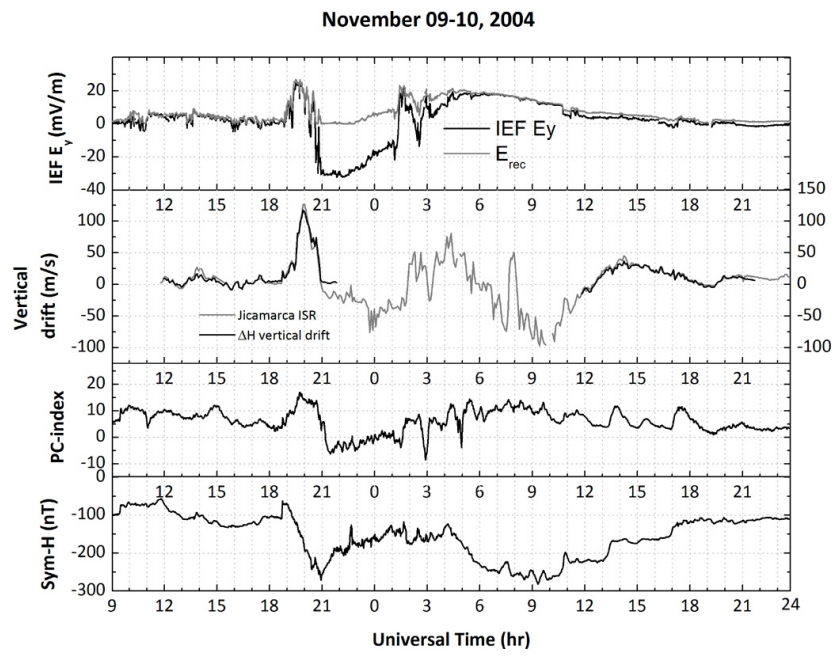

Fig. 9. From top to bottom: Interplanetary Electric Field (IEF) $E_{\mathrm{y}}$ and $E_{\text {rec }}$ for 9-10 November 2004; Vertical drifts over Jicamarca (black line denotes vertical drifts inferred from magnetometer data, gray line indicates Jicamarca ISR measured average vertical drifts); PC-index showing the polar cap activity; and Sym-H geomagnetic index showing the geomagnetic storm occurred on 9-10 November.

fountain effect" (Tsurutani et al., 2004; Horvath and Lovell, 2008).

In the post-midnight sector on 10 November, a series of rapid raise and/or decay in the vertical drifts are remarkable, as we can see from Fig. 9. The vertical drifts remain predominantly positive during the night. One interpretation for this result is the combined effects of disturbance dynamo mechanism (eastward zonal electric field during the night) and PPEFs. There is a clear correspondence between IEF and the vertical drifts from 19:00 UT on 9 November until 05:00 UT (00:00 LT - Jicamarca) on 10 November, considering the changing in the sign (near midnight local time) of this correlation around 04:00 UT. It is necessary to mention that the relationship is not linear and has different efficiency of penetration during this time interval. This nonlinear efficiency is attributed to the local time dependence of the PPEFs (Fejer et al., 2007; Kelley et al., 2010). Long duration PPEFs have been reported in the literature and are a plausible mechanism to explain the correlation during this time interval (Huang et al., 2005a). Also, another interpretation for this event is that the vertical drifts may be the result of a series of PPEFs, considering the occurrence of continuing "undershielding" and "overshielding" events. The positive vertical drifts during the night were also detected over the Brazilian region, as Fig. 5 (bottom panel) shows (F layer uplift during the night).

Figure 11 shows the TEC map for 10 November at 16:00 UT (11:00 LT - Jicamarca, 13:00 BST) and 22:00 UT (17:00 LT - Jicamarca, 19:00 BST). The vertical drifts (Jicamarca) shown in Fig. 9 during daytime on 10 November present a partial recovery of the quiet time patterns 


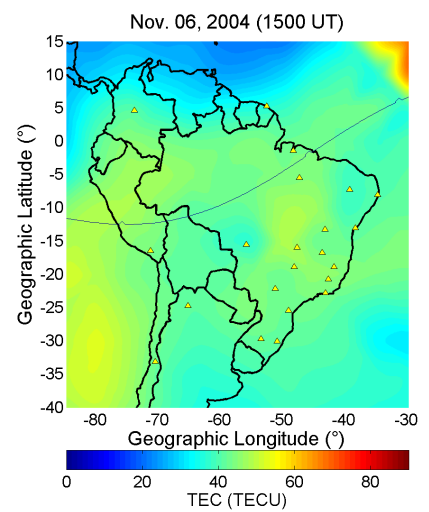

(a)

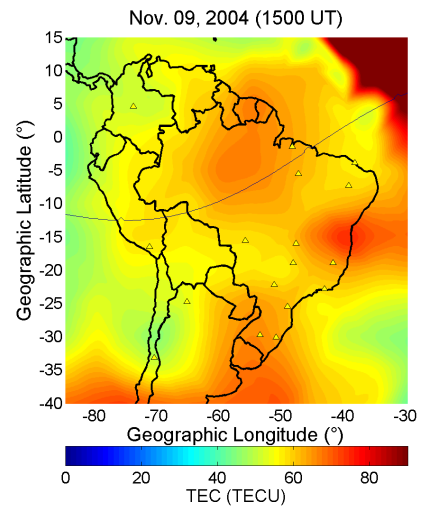

(e)

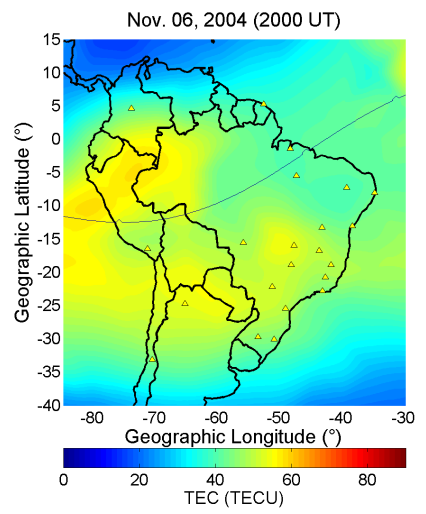

(b)

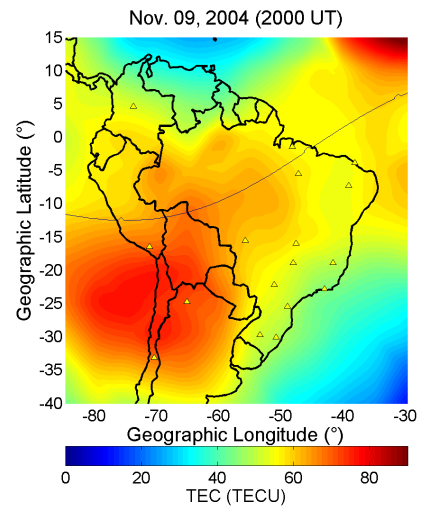

(f)

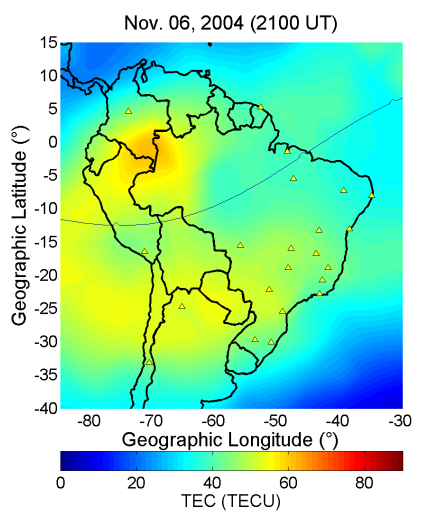

(c)

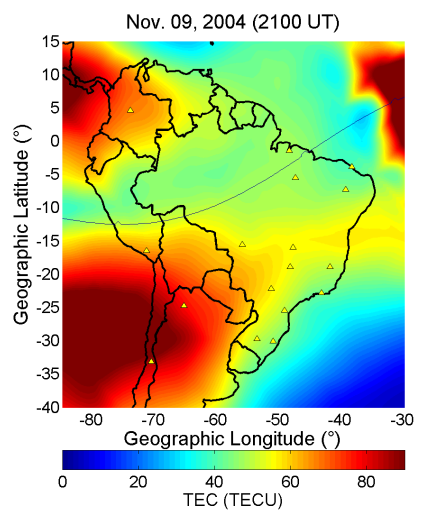

(g)

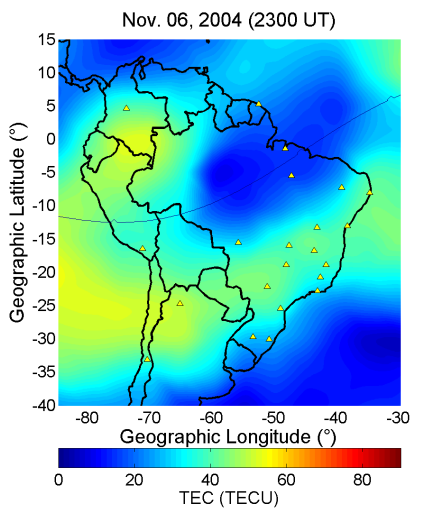

(d)

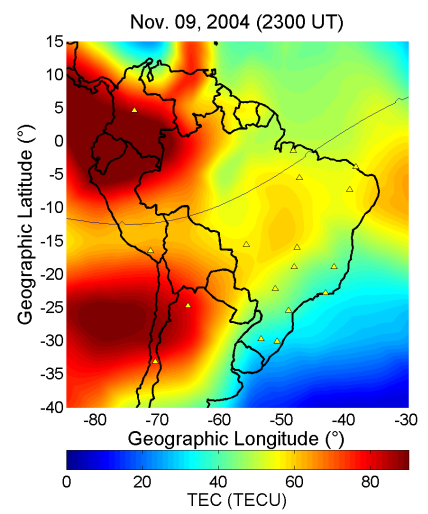

(h)

Fig. 10. TEC evolution for 9-10 November 2004. Top: TEC maps for 6 November (quiet day) at 15:00 UT (12:00 BST), 20:00 UT (17:00 BST), 21:00 UT (18:00 BST), and 22:00 UT (19:00 BST) (from a to d, respectively). Bottom: TEC maps at the respective hours for 9 November (from $\mathbf{e}$ to $\mathbf{h}$ ).

$\left(\sim 20 \mathrm{~m} \mathrm{~s}^{-1}\right)$ but with the absence of the pre-reversal enhancement. On the other hand we can see the suppression of EIA added to a confined TEC distribution over the geomagnetic equator compared to the quiet day. The suppression of EIA prevailed during the whole day but TEC over the geomagnetic equator exhibited higher daytime values contrasting to the quiet day. Figure 5 (bottom panel) also shows the absence of pre-reversal enhancement in the Brazilian region which supports the suppression of EIA. Mannucci et al. (2009) reported a decrease in the ratio $\mathrm{O} / \mathrm{N}_{2}$ during 10 November for the geographic latitudes under $\sim 20^{\circ} \mathrm{S}$, which was the most plausible explanation for the suppression of EIA and TEC decrease from low to middle latitudes seen in Fig. 11. This remarkable decrease in TEC during 10 November is an indicator of the ionospheric storm negative phase, during which the long lasting disturbed thermospheric winds and compositions changes are predominant over the electric fields.

\section{Remarks and conclusions}

The November 2004 superstorm was marked out with recurrent Sym-H descendings and main phases lasting about 1 day (8 November and 10 November). This very disturbed period was responsible to create an ionospheric-thermospheric condition characterized by stressed modifications in electric fields (equatorial vertical drifts) and neutral composition changes.

Before the sudden storm commencement on 7 November, the vertical drifts already showed a disturbed pattern denoted by a prompt penetration electric field event that raised the vertical drift to $\sim 35 \mathrm{~m} \mathrm{~s}^{-1}$. This PPEF caused no significant TEC response. After that, the vertical drifts became negative during daytime, being related to an westward zonal electric field that was probably the cause of an inhibition of the EIA during post-sunset hours. This may be related to a fast disturbance dynamo resulting from the energy input in the polar caps due to a $B_{\mathrm{Z}}$ southward turning and its consequent PPEF that was previously mentioned. 

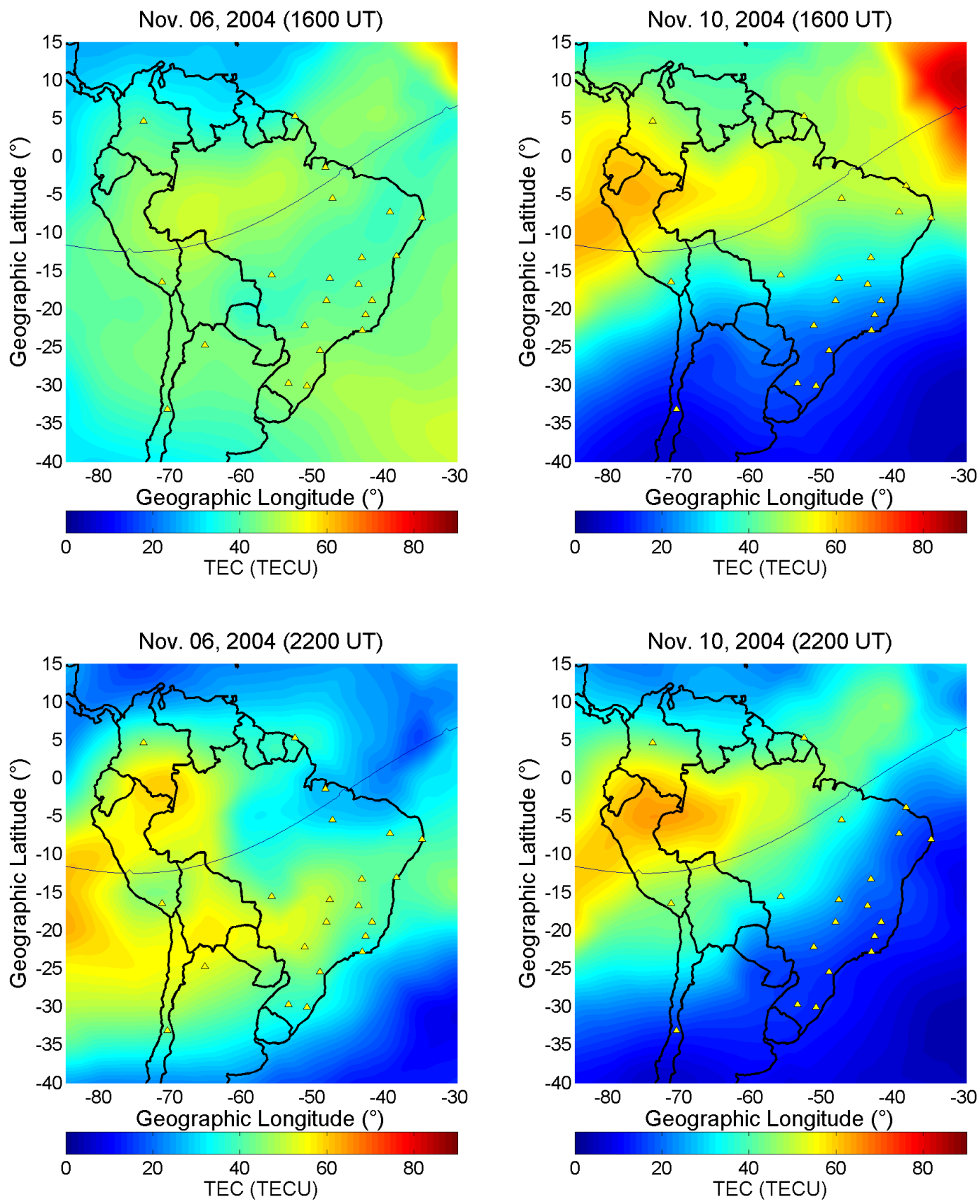

Fig. 11. Left: TEC maps for 6 November (quiet day) at 16:00 UT (13:00 BST) (top panel) and 22:00 UT (19:00 BST) (bottom panel). Right: respective TEC response on 10 November.

The enhanced TEC observed in the first hours on 8 November were probably due to an PPEF event which caused an eastward electric field on the post-sunset sector raising the $\mathrm{F}$ layer and intensificating the EIA development. Although, the quiet time pattern also shows a weaker EIA development for these hours, which is a late response of plasma difusion due to the pre-reversal enhancement. EIA development is noticeable on 8 November after 22:30 UT (17:30 LT - Jicamarca; 19:30 BST), resulting from a slight raise of ver- tical drifts. In contrast, higher vertical drifts resulting from a penetration event were observed in the evening on 7 November but were not sufficient to develop the EIA.

On 9 November, a great penetration electric field which raised the vertical drifts to $\sim 120 \mathrm{~m} \mathrm{~s}^{-1}$ was observed. This event reports a much higher penetration efficiency from IEF to equatorial electric fields compared to the penetration that occurred on 7 November. Consequently, by considering the results of this whole event, it was not possible to compute 
the magnitude of the ionospheric electric field by considering only proportionality factors (Kelley et al., 2003), owing to the complex dynamic factors that are involved during penetration of an electric field. On this day, the superfountain effect was attributed to raise the ionosphere to higher altitudes where the recombination is less effective, causing the TEC absolute values to remain higher over equatorial and low latitude sectors than the quiet time pattern. At this point we can also consider the disturbed thermospheric winds and composition changes as possible contributions for the TEC changes.

On 10 November, the ionospheric responses are characterized by lower TEC (from low to mid-latitudes) and EIA inhibition denoting a dominant disturbance dynamo mechanism associated to the non-electrodynamic forcing. These two components prevail in the ionospheric negative phase scenario. Though the vertical drifts assumed a near quiet time pattern, except for the absence of pre-reversal enhancement, there was no response on TEC maps of this electrodynamic recovery, and the likely disturbed winds and composition changes (non-electrodynamic forcing) dominated the TEC response. These "late time" features represent the negative phase of the ionospheric storm.

In this study the total electron content during the superstorm presented both expected and unexpected responses that are very useful to test our current understanding of ionspheric dynamics during these events and also to address some objectives for future works. The use of the expanded IBGE (Brazil) network of GPS receivers will be an improvement in the TEC related studies in the South America region during the next solar maximum activity period.

Acknowledgements. The author is grateful to Conselho Nacional de Desenvolvimento Científico e Tecnológico (CNPq) under the process 142915/2008-4 and to the Jicamarca Radio Observatory for providing the ISR data and magnetometer data. The Jicamarca Radio Observatory is a facility of the Instituto Geofisico del Peru and is operated with support from the NSF Cooperative Agreement ATM0432565 through Cornell University.

Topical Editor K. Kauristie thanks O. Verkhoglyadova and another anonymous referee for their help in evaluating this paper.

\section{References}

Abdu, M. A.: Major phenomena of the equatorial ionospheretermosphere system under disturbed conditions, J. Atmos. Sol. Terr. Phys., 59, 1505-1519, 1997.

Abdu, M. A, Walker, G. O., Reddy, B. M., de Paula E. R., Sobral, J. H. A., Fejer, B. G., and Szuszczewicz, E. P.: Global scale equatorial ionization anomaly (EIA) response to magnetospheric disturbances based on the May-June 1987 SUNDIAL-coordinated observations, Ann. Geophys., 11, 585-594, 1993.

Anderson, D., Anghel, A., Chau, J., and Veliz, O.: Daytime vertical $\mathrm{E} \times \mathrm{B}$ drift velocities inferred from ground based magnetometer observations at low latitudes, Space Weather, 2, S11001, doi:10.1029/2004SW000095, 2004.
Basu, S., Basu, S., Valladares, C. E., Yeh, H.-C., Su, S.-Y., MacKenzie, E., Sultan, P. J., Aarons, J., Rich, F. J., Doherty, P., Groves, K. M., and Bullett, T. W.: Ionospheric effects of major magnetic storms during the International Space Weather Period of September and October 1999: GPS observations, VHF/UHF scintillations, and in situ density structures at middle and equatorial latitudes, J. Geophys. Res., 106, 30389-30413, 2001.

Bittencourt, J. A. and Abdu, M. A.: A theoretical comparison between apparent and real vertical ionization drift velocities in the equatorial F region, J. Geophys. Res., 86, 2451-2454, 1981.

Blanc, M.: Magnetospheric convection effects at mid-latitudes, 1 . Saint-Santin observations, J. Geophys. Res., 88, 211-213, 1983.

Blanc, M. and Richmond, A. D.: The ionospheric disturbance dynamo, J. Geophys. Res., 85, 1669-1686, 1980.

Buonsanto, M. J.: Ionospheric Storms - A review, Space Sci. Rev., 88, 563-601, doi:10.1023/A:1005107532631, 1999.

Burton, R. K., McPherron, R. L., and Russell, C. T.: Terrestrial magnetosphere: a half-wave rectifier of the interplanetary electric field, Science, 189, 717-718, 1975.

de la Beaujardiere, O., Watermann, J., Newell, P., and Rich, F.: Relationship between Birkeland current regions, particle precipitation, and electric fields, J. Geophys. Res., 98, 7711-7720, 1993.

Echer, E., Tsurutani, B. T., and Guarnieri, F. L.: Interplanetary origins of November 2004 superstorms, J. Atmos. Sol. Terr. Phys., 72, 280-284, 2010.

Fejer, B. G.: Equatorial ionospheric electric fields associated with magnetospheric disturbances, in: Solar Wind-Magnetosphere Coupling, edited by: Kamide, Y. and Slavin, J. A., pp. 519-545, Terra Sci., Tokyo, 1986.

Fejer, B. G.: The electrodynamics of the low-latitude ionosphere: Recent results and future challenges, J. Atmos. Sol. Terr. Phys., 59, 1465-1482, 1997.

Fejer, B. G.: Low latitude storm time ionospheric electrodynamics, J. Atmos. Sol.Terr. Phys., 64, 1401-1408, 2002.

Fejer, B. G. and Scherliess, L.: Empirical models of storm time equatorial electric fields, J. Geophys. Res., 102, 24047-24056, 1997.

Fejer, B. G., Jensen, J. W., Kikuchi, T., Abdu, M. A., and Chau, J. L.: Equatorial Ionospheric Electric Fields during the November 2004 Magnetic Storm, J. Geophys. Res., 112, A10304, doi:10.1029/2007JA012376, 2007.

Foster, J. and Rich, F.: Prompt midlatitude electric field effects during severe geomagnetic storms, J. Geophys. Res., 103, 2636726372, 1998.

Fuller-Rowell, T. J., Codrescu, M. V., Roble, R. G., and Richmond, A. D.: How does the thermosphere and ionosphere react to a geomagnetic storm?, in: Magnetic Storms, Geophys. Monogr. Ser., vol. 98, edited by: Tsurutani, B. T., Gonzalez, W. D., Kamide, Y., and Arballo, J. K., AGU, Washington, D.C., 1997.

Fuller-Rowell, T. J., Millward, G. H., Richmond, A. D., and Codrescu, M. V.: Storm-time changes in the upper atmosphere at low latitudes, J. Atmos. Sol. Terr. Phys., 64, 1383-1391, 2002.

Gonzalez, W. D. and Tsurutani, B. T.: Criteria of interplanetary parameters causing intense magnetic storms (Dst $<-100 \mathrm{nT}$ ), Planet. Space Sci., 35, 1101-1109, 1987.

Gonzales, C. A., Kelley, M. C., Fejer, B. G., Vickrey, J. F., and Woodman, R. F.: Equatorial electric fieds during magnetically disturbed conditions, II. Implications of simultaneous auroral and equatorial measurements, J. Geophys. Res., 84, 5803-5812, 
1979.

Gonzalez, W. D., Joselyn, J. A., Kamide, Y., Kroehl, H. W., Rostoker, G., Tsurutani, B. T., and Vasyliunas, V. M.: What is a geomagnetic storm?, J. Geophys. Res., 99, 5771-5792, doi:10.1029/93JA02867, 1994.

Heelis, R. A. and Coley, W. R.: East-west ion drifts at mid-latitudes observed by Dynamics Explorer 2, J. Geophys. Res., 97, 1946119469, 1992.

Horvath, I. and Lovell, B. C.: Formation and evolution of the ionospheric plasma density shoulder and its relationship to the superfountain effects investigated during the 6 November 2001 great storm, J. Geophys. Res., 113, A12315, doi:10.1029/2008JA013153, 2008.

Huang, C.-S., Foster, J. C., and Kelley, M. C.: Long-duration penetration of the interplanetary electric field to the low-latitude ionosphere during the main phase of magnetic storms, J. Geophys. Res., 110, A11309, doi:10.1029/2005JA011202, 2005a.

Huang, C.-S., Foster, J. C., Yumoto, K., Chau, J. L., and Veliz, O.: Prompt effects of solar wind variations on the inner magnetosphere and midlatitude ionosphere, Adv. Space Res., 36, 24072412, 2005b.

Huba, J. D., Joyce, G., Sazykin,S., Wolf, R., and Spiro, R.: Simulation study of penetration electric field effects on the lowto mid-latitude ionosphere, Geophys. Res. Lett., 32, L23101, doi:10.1029/2005GL024162, 2005.

Iyemori, T.: Storm-time magnetospheric currents inferred from midlatitude geomagnetic field variations, J. Geomagn. Geoelectr., 42, 1249-1265, 1990.

Kelley, M. C., Fejer, B. G., and Gonzales, C. A.: An explanation for anomalous ionospheric electric fields associated with a northward turning of the interplanetary magnetic field, Geophys. Res. Lett., 6, 301-304, 1979.

Kelley, M. C., Makela, J. J., Chau, J. L., and Nicolls, M. J.: Penetration of the solar wind electric field into the magnetosphere/ionosphere system, Geophys. Res. Lett., 30, 1158, doi:10.1029/2002GL016321, 2003.

Kelley, M. C., Ilma, R. R., Nicolls, M., Erickson, P., Goncharenko, L., Chau, J. L., Aponte, N., and Kozyra, J. U.: Spectacular lowand mid-latitude electrical fields and neutral winds during a superstorm, J. Atmos. Sol. Terr. Phys., 72, 285-291, 2010.

Komjathy, A.: Global Ionospheric Total Electron Content Mapping Using the Global Positioning System, PhD dissertation, Department of Geodesy and Geomatics Engineering Technical Report No. 188, University of New Brunswick, Fredericton, New Brunswick, Canada, 248 pp., 1997.

Lin, C. H., Richmond, A. D., Heelis, R. A., Bailey, G. J., Lu, G., Liu, J. Y., Yeh, H. C., and Su, S.-Y.: Theoretical study of the low- and midlatitude ionospheric electron density enhancement during the October 2003 superstorm: Relative importance of the neutral wind and the electric field, J. Geophys. Res., 110, A12312, doi:10.1029/2005JA011304, 2005.

Mannucci, A. J., Tsurutani, B. T., Iijima, B. A., Komjathy, A., Saito, A., Gonzalez, W. D., Guarnieri, F. L., Kozyra, J. U., and Skoug, R.: Dayside global ionospheric response to the major interplanetary events of October 29-30, 2003 "Halloween Storms", Geophys. Res. Lett., 32, L12S02, doi:10.1029/2004GL021467, 2005.

Mannucci, A. J., Tsurutani, B. T., Abdu, M. A., Gonzalez, W. D., Komjathy, A., Echer, E., Iijima, B. A., Crowley, G., and Ander- son, D.: Superposed epoch analysis of the dayside ionospheric response to four intense geomagnetic storms, J. Geophys. Res., 113, A00A02, doi:10.1029/2007JA012732, 2008.

Mannucci, A. J., Tsurutani, B. T., Kelley, M. C., Iijima, B. A., and Komjathy, A.: Local time dependence of the prompt ionospheric response for the 7, 9, and 10 November 2004 superstorms, J. Geophys. Res., 114, A10308, doi:10.1029/2009JA014043, 2009.

Mendillo, M.: Storms in the ionosphere: Patterns and processes for total electron content, Rev. Geophys., 44, RG4001, doi:10.1029/2005RG000193, 2006.

Muella, M. T. A. H., Kherani, E. A., de Paula, E. R., Cerruti, A. P., Kintner, P. M., Kantor, I. J., Mitchell, C. N., Batista, I. S., and Abdu, M. A.: Scintillation-producing Fresnel-scale irregularities associated with the regions of steepest TEC gradients adjacent to the equatorial ionization anomaly, J. Geophys. Res., 115, A03301, doi:10.1029/2009JA014788, 2010.

Nishida, A.: Coherence of geomagnetic DP 2 fluctuations with interplanetary magnetic variations, J. Geophys. Res., 73, 55495559, 1968.

Prölss, G. W.: Ionospheric F-region storms, in: Handbook of Atmospheric Electrodynamics, Vol. 2, edited by: Volland, H., CRC Press, Boca Raton, 195-248, 1995.

Pulkkinen, T. I., Ganushkina, N. Yu., Kallio, E. I., Lu, G., Baker, D. N., Turner, N. E., Fritz, T. A., and Fennell, J. F., Roeder, J.: J. Energy Dissipation During the Geomagnetic Storm: May 1998, Adv. Space Res., 30, 2231-2240, 2002.

Rastogi, R. G. and Klobuchar, J. A.: Ionospheric electron content within the equatorial F2 layer anomaly belt, J. Geophys. Res. 95, 19045-19052, 1990.

Reddy, C. A., Somayajulu, V. V., and Devasia, C. V.: Global scale electrodynamic coupling of the auroral and equatorial dynamo regions, J. Atmos. Terr. Phys., 41, 189-201, 1979.

Rishbeth, H.: F-region storms and thermospheric circulation, J. Atmos. Terr. Phys., 37, 1055-1064, 1975.

Sahai, Y., Becker-Guedes, F., Fagundes, P. R., de Jesus, R., de Abreu, A. J., Paxton, L. J., Goncharenko, L. P., Brunini, C., Gende, M., Ferreira, A. S., Lima, N. S., Guarnieri, F. L., Pillat, V. G., Bittencourt, J. A., and Candido, C. M. N.: Effects observed in the Latin American sector ionospheric F region during the intense geomagnetic disturbances in the early part of November 2004, J. Geophys. Res., 114, A00A19, doi:10.1029/2007JA013007, 2009.

Scherliess, L. and Fejer, B. G.: Storm time dependence of equatorial disturbance dynamo zonal electric fields, J. Geophys. Res., 102, 24037-24046, 1997.

Tsurutani, B. T., Manucci, A., Iijima, B., Abdu, M. A., Sobral, J. H. A., Gonzalez, W., Guarnieri, F., Tsuda, T., Saito, A., Yumoto, K., Fejer, B. G., Fuller-Rowell, T. J., Kozyra, J., Foster, J. C., Coster, A., and Vasyliunas, V. M.: Global dayside ionosphere uplift and enhancement associated with interplanetary electric fields, J. Geophys. Res., 109, A08302, doi:10.1029/2003JA010342, 2004.

Tsurutani, B. T., Verkhoglyadova, O. P., Mannucci, A. J., Araki, T., Sato, A., Tsuda, T., and Yumoto, K.: Oxygen ion uplift and satellite drag effects during the 30 October 2003 daytime superfountain event, Ann. Geophys., 25, 569-574, doi:10.5194/angeo25-569-2007, 2007.

Tsurutani, B. T., Verkhoglyadova, O. P., Mannucci, A. J., Saito, A., Araki, T., Yumoto, K., Tsuda, T., Abdu, M. A., Sobral, J. H. A., Gonzalez, W. D., McCreadie, H., Lakhina, G. 
S., and Vasyliūnas, V. M.: Prompt penetration electric fields (PPEFs) and their ionospheric effects during the great magnetic storm of 30-31 October 2003, J. Geophys. Res., 113, A05311, doi:10.1029/2007JA012879, 2008a.

Tsurutani, B. T., Echer, E., Guarnieri, F. L., and Kozyra, J. U.: CAWSES November 7-8, 2004, superstorm: Complex solar and interplanetary features in the post-solar maximum phase, Geophys. Res. Lett., 35, L06S05, doi:10.1029/2007GL031473, 2008b.
Vasyliūnas, V. M.: Electric field and plasma flow: What drives what?, Geophys. Res. Lett., 28, 2177-2180, 2001.

Vasyliūnas, V. M.: Time evolution of electric fields and currents and the generalized Ohm's law, Ann. Geophys., 23, 1347-1354, doi:10.5194/angeo-23-1347-2005, 2005a.

Vasyliūnas, V. M.: Relation between magnetic fields and electric currents in plasmas, Ann. Geophys., 23, 2589-2597, doi:10.5194/angeo-23-2589-2005, 2005b.

Woodman, R. F.: Vertical drifts and east-west electric fields at the magnetic equator, J. Geophys. Res., 75, 6249-6259, 1970. 